\title{
Stable Mossy Fiber Long-Term Potentiation Requires Calcium Influx at the Granule Cell Soma, Protein Synthesis, and Microtubule-Dependent Axonal Transport
}

\author{
Steven J. Barnes, ${ }^{1,3 *}$ Thoralf Opitz, ${ }^{1 \star}$ Malte Merkens, ${ }^{1}$ Tony Kelly, ${ }^{1}$ Christian von der Brelie, ${ }^{1,2}$ Roland Krueppel, ${ }^{1}$ \\ and Heinz Beck ${ }^{1}$ \\ Departments of ${ }^{1}$ Epileptology and ${ }^{2}$ Neurosurgery, University of Bonn, D-53105 Bonn, Germany, and ${ }^{3}$ Department of Psychology, University of British \\ Columbia, Vancouver, British Columbia V6T 1Z4, Canada
}

The synapses formed by the mossy fiber (MF) axons of hippocampal dentate gyrus granule neurons onto CA3 pyramidal neurons exhibit an intriguing form of experience-dependent synaptic plasticity that is induced and expressed presynaptically. In contrast to most other CNS synapses, long-term potentiation (LTP) at the MF-CA3 synapse is readily induced even during blockade of postsynaptic glutamate receptors. Furthermore, blocking voltage-gated $\mathrm{Ca}^{2+}$ channels prevents MF-LTP, supporting an involvement of presynaptic $\mathrm{Ca}^{2+}$ signaling via voltage-gated $\mathrm{Ca}^{2+}$ channels in MF-LTP induction. We examined the contribution of activity in both dentate granule cell somata and MF terminals to MF-LTP. We found that the induction of stable MF-LTP requires tetanization-induced action potentials not only at MF boutons, but also at dentate granule cell somata. Similarly, blocking $\mathrm{Ca}^{2+}$ influx via voltage-gated $\mathrm{Ca}^{2+}$ channels only at the granule cell soma was sufficient to disrupt MF-LTP. Finally, blocking protein synthesis or blocking fast axonal transport mechanisms via disruption of axonal tubulin filaments resulted in decremental MF-LTP.

Collectively, these data suggest that-in addition to $\mathrm{Ca}^{2+}$ influx at the MF terminals-induction of MF synaptic plasticity requires action potential-dependent $\mathrm{Ca}^{2+}$ signaling at granule cell somata, protein synthesis, and fast axonal transport along MFs. A parsimonious interpretation of these results is that somatic activity triggers protein synthesis at the soma; newly synthesized proteins are then transported to MF terminals, where they contribute to the stabilization of MF-LTP. Finally, the present data imply that synaptic plasticity at the MF-CA3 synapse can be affected by local modulation of somatic and presynaptic $\mathrm{Ca}^{2+}$ channel activity.

\section{Introduction}

Plasticity at CNS synapses is thought to play a crucial role in the encoding and storage of information. While most synapses have the capacity to exhibit long-term increases (e.g., long-term potentiation; LTP) or decreases (e.g., long-term depression; LTD) in synaptic strength, the mechanisms underlying the induction and expression of these forms of plasticity are diverse. At many synapses, LTP induction requires the postsynaptic activation of NMDA-type glutamate receptors or $\mathrm{Ca}^{2+}$ channels during tetanic stimulation (Madison et al., 1991). The ensuing postsynaptic $\mathrm{Ca}^{2+}$ influx triggers various $\mathrm{Ca}^{2+}$-dependent signaling cascades that lead to the subsequent expression of LTP (Nicoll, 2003).

In other forms of LTP, induction and expression do not necessarily occur postsynaptically. For example, the induction of LTP at the mossy fiber (MF) synapse (MF-LTP) of the hippocampus is unaffected by the pharmacological blockade

\footnotetext{
Received April 12, 2010; revised June 22, 2010; accepted Aug. 6, 2010.

This work was supported by the Deutsche Forschungsgemeinschaft (SFB TR3), EPICURE, ERANET Neuron "EpiNet," Marie Curie Actions, and the BONFOR program of the University of Bonn Medical Center.

*S.J.B. and T.0. contributed equally to this work.

Correspondence should be addressed to Heinz Beck, Department of Epileptology, Laboratory of Experimental Epileptology, Sigmund-Freud-Strasse 25, 53127 Bonn, Germany. E-mail: heinz.beck@ukb.uni-bonn.de. DOI:10.1523/JNEUROSCI.1847-10.2010

Copyright $\odot 2010$ the authors $\quad 0270-6474 / 10 / 3012996-09 \$ 15.00 / 0$
}

of postsynaptic NMDA and/or AMPA receptors [e.g., see Castillo et al. (1994), Nicoll and Malenka (1995), and Mellor and Nicoll (2001); for a review, see Nicoll and Schmitz (2005)]. In addition, MF-LTP persists even when postsynaptic $\mathrm{Ca}^{2+}$ signaling is interrupted by the introduction of high-affinity $\mathrm{Ca}^{2+}$ buffers into the postsynaptic CA3 neurons (Mellor and Nicoll, 2001) (but see Yeckel et al., 1999). MF-LTP is, however, disrupted or modified by the pharmacological blockade or the genetic deletion of the voltage-gated $\mathrm{Ca}^{2+}$ channel subtypes that are present in MF terminals (Castillo et al., 1994; Dietrich et al., 2003). Furthermore, MF-LTP is significantly reduced in mutant mice strains with deletions or modifications of components of the presynaptic neurotransmitter release machinery (Castillo et al., 1997; Castillo et al., 2002).

In general, it seems that postsynaptic signaling mechanisms are not important for the induction of MF-LTP, whereas presynaptic $\mathrm{Ca}^{2+}$ channels are. However, the aforementioned pharmacological and genetic manipulations of the MF presynaptic $\mathrm{Ca}^{2+}$ channels would have caused a general reduction of $\mathrm{Ca}^{2+}$ influx in the presynaptic cell, not just at the presynaptic terminals. Thus, it is unclear whether it is the $\mathrm{Ca}^{2+}$ increase in MF boutons that is crucial for LTP induction, or whether $\mathrm{Ca}^{2+}$ increases in other subcellular compartments of the presynaptic neuron are critical. We designed a series of experiments to selectively investigate the roles of dentate granule cell 

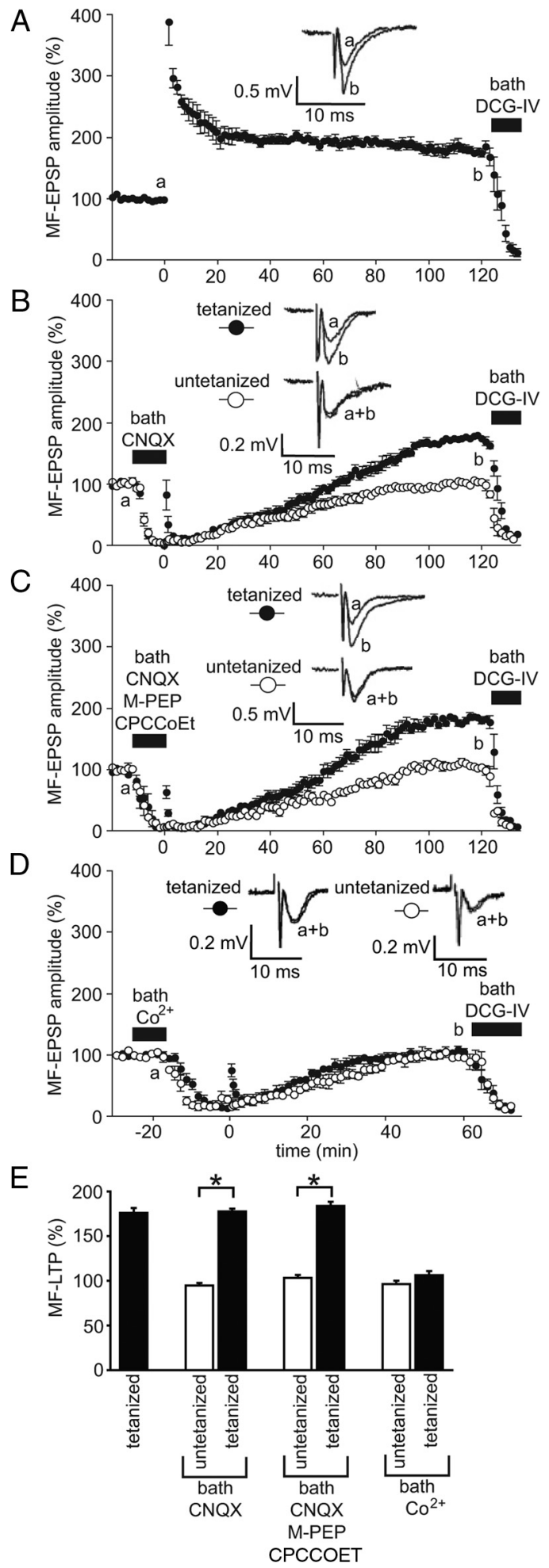

Figure 1. Activation of postsynaptic CA3 pyramidal cells is not necessary for mossy fiber long-term potentiation. $A$, Time course of the amplitude of the EPSPs recorded at the MF pathway. Tetanization ( $4 \times 50$ stimuli, $100 \mathrm{~Hz}$, delivered at time point zero) induced an LTP of MF-EPSPs during the recording period of $2 \mathrm{~h}$. Bath application of the selective $m G$ luR-2 agonist DCG-IV $(3 \mu \mathrm{M})$ dramatically reduced MF-EPSP amplitudes and verified that our recording had little contamination from other pathways. Insets show representative sample traces obtained at the time points indicated by the lowercase letters. $\boldsymbol{B}$, Time course of MF-EPSP amplitudes with tetanization (filled circles) or without (empty circles) tetanization. Bath application of 25 $\mu_{M}$ CNQX (filled bar) during the tetanus dramatically reduced the amplitude of MF-EPSPs. After washout of CNQX, there was a large potentiation of MF-EPSPs present in the tetanized slices versus the untetanized control slices. C, Time course of the amplitude of the EPSPs recorded at somata versus MF boutons in the induction and expression of MF-LTP. We found that, in addition to action potential firing at MF terminals, activity and concomitant $\mathrm{Ca}^{2+}$ influx at granule cell somata also play a critical role in MF-LTP induction. Furthermore, our data suggest that fast axonal transport links somatic induction mechanisms to the plasticity occurring at MF terminals.

\section{Materials and Methods}

Subjects. Experiments were performed on male C57BL/6 mice (Charles River) that were $29-55 \mathrm{~d}$ old at the beginning of each experiment. Mice were group housed in wire-lidded plastic cages before each experiment and had continuous access to food and water under a 12:12 h light-dark cycle. All experimental procedures were approved by the University of Bonn Animal Care and Use Committee.

Hippocampal slice preparation and maintenance. Hippocampal slice preparations were performed during the light phase of the light-dark cycle. Each mouse was perfused through the left ventricle of their heart with 5-15 $\mathrm{ml}$ of ice-cold carbogen (i.e., $95 \% \mathrm{O}_{2}, 5 \% \mathrm{CO}_{2}$ )bubbled dissection fluid ( $40 \mathrm{~mm} \mathrm{NaCl}, 2.5 \mathrm{~mm} \mathrm{KCl}, 25 \mathrm{~mm} \mathrm{NaHCO}_{3}$, $1.25 \mathrm{~mm} \mathrm{NaH}_{2} \mathrm{PH}_{4}, 0.5 \mathrm{~mm} \mathrm{CaCl}_{2}, 7 \mathrm{mM} \mathrm{MgCl}_{2}, 25 \mathrm{~mm}$ D-glucose, and $150 \mathrm{~mm}$ sucrose; pH 7.4), under combined ketamine (Upjohn: 100 $\mathrm{mg} / \mathrm{kg}$, i.p.) and xylazine (Bayer: $80 \mathrm{mg} / \mathrm{kg}$, i.p.) anesthesia. Next, the mouse was decapitated, its brain was removed and immediately immersed in ice-cold carbogen-bubbled dissection fluid. Finally, transverse $400 \mu \mathrm{m}$ hippocampal slices were cut from the brain using a vibratome (either a VT 1000S, Leica, or a Microm HM650V) and directly transferred into a holding chamber that contained carbogenbubbled room-temperature artificial CSF (ACSF; $125 \mathrm{~mm} \mathrm{NaCl}, 3 \mathrm{~mm}$ $\mathrm{KCl}, 26 \mathrm{~mm} \mathrm{NaHCO}, 1.25 \mathrm{~mm} \mathrm{NaH} \mathrm{PH}_{4}, 2.5 \mathrm{~mm} \mathrm{CaCl}_{2}, 1.3 \mathrm{~mm}$ $\mathrm{MgCl}_{2}$, and $25 \mathrm{~mm}$ D-glucose; $\mathrm{pH} 7.4$ ).

Stimulation and field EPSP recording. Not less than $1 \mathrm{~h}$ after the preparation of the hippocampal slices, a single hippocampal slice was transferred into the recording chamber. Once in the recording chamber, the slices were continuously superfused $(2-2.5 \mathrm{ml} / \mathrm{min})$ with carbogen-bubbled ACSF. The temperature in the recording chamber was between $31^{\circ}$ and $33^{\circ} \mathrm{C}$. MFs were stimulated via a monopolar glass stimulation electrode filled with ACSF $(\sim 3 \mathrm{M} \Omega)$ placed in the stratum lucidum of the CA3 region of the hippocampus. In some experiments, stimulation of MFs was performed by placing a bipolar stimulation electrode within the granule cell layer. Paired-pulse stimulations (40 ms apart, every $30 \mathrm{~s}$ ) were delivered with a constantcurrent stimulus isolator (WPI A320; 0.1-0.3 mA, $100 \mu \mathrm{s}$ ). MF field EPSPs (MF-EPSPs) were recorded with an ACSF-filled borosilicate glass pipette $(3 \mathrm{M} \Omega$ ) placed within the CA3 stratum lucidum. Three criteria were used to ensure the MF origin of the recorded EPSPs. First, the EPSPs had to exhibit a paired-pulse facilitation of at least $250 \%$. Second, the EPSPs had to display facilitation in response to 1 $\mathrm{Hz}$ stimulation of at least $450 \%$. Third, bath application of $\left(2 S, 2^{\prime} R, 3^{\prime} R\right)-2-\left(2^{\prime}, 3^{\prime}\right.$-dicarboxycyclopropyl) glycine (DCG-IV, 3 $\mu \mathrm{M})$, which was performed at the end of all MF recordings, had to block the putative MF-EPSPs by at least $80 \%$. A $25 \mu \mathrm{M}$ concentration of D-AP5 was present in the bath ACSF for some of the experiments (i.e., for those experiments presented in Figs. 1 and 3). PP-EPSPs were

the MF pathway. Tetanized slices (filled circles) were compared to untetanized controls (unfilled circles). Bath application of the selective mGluR1 and 5 antagonists MPEP (10 $\mu \mathrm{M})$ and $\mathrm{CPCCOEt}$ $(100 \mu \mathrm{m})$ along with CNQX (25 $\mu \mathrm{m}$; filled bar) during the tetanus dramatically reduced the amplitude of MF-EPSPs. After washout of the blockers, there was a large potentiation of MFEPSPs present in tetanized relative to untetanized control slices. D, Time course of the amplitude of the EPSPs recorded at the MF pathway. Tetanized (filled circles) slices were compared to untetanized control slices (unfilled circles). Bath application of the $\mathrm{Ca}^{2+}$ channel blocker $\mathrm{Co}^{2+}$ (filled bar) during the tetanus yielded no difference in the size of MF-EPSPs in tetanized versus untetanized controls. $\boldsymbol{E}$, Summary of the amount of MF-LTP present in the results presented in $\boldsymbol{A}-\boldsymbol{D}$. Asterisks indicate significant $(p<0.05)$ differences in the amount of LTP displayed by tetanized (filled bars) versus untetanized control (open bars) slices. 
recorded by placing stimulation and recording electrodes within the molecular layer of the dentate gyrus. Antidromic dentate granule cell population spikes were recorded by placing a recording electrode within the dentate granule cell layer.

Focal drug applications were administered with a Picospritzer (Intracel, Shepreth). The Picospritzer was used to apply brief pulses of air pressure to patch pipettes that were filled with an ACSF-based drug solution. Depending on the particular experiment, that drug solution included either $10 \mu \mathrm{M}$ TTX, $5 \mathrm{mM} \mathrm{Co}^{2+}$, or an ACSF with $\mathrm{NaCl}$ replaced by $125 \mathrm{~mm}$ choline chloride. In some experiments, a 0 $\mathrm{Ca}^{2+}$-containing extracellular ACSF was applied directly via the field potential recording electrode via application of mild pressure (30-40 mbar).

MF tetanic stimulation consisted of 4 trains of 50 pulses at $100 \mathrm{~Hz}$ that were delivered $1 \mathrm{~s}$ apart and were of the same intensity as the MF baseline test stimuli. Analog data were digitized and stored for offline analysis (Digidata 1200A or 1322, pCLAMP 7 or 8, Molecular Devices). fEPSP peaks were normalized to baseline values and depicted as average \pm SEM. The glutamate receptor ligands 2-methyl-6-(phenylethynyl)pyridine (MPEP), 7-(hydroxyimino)-cyclopropa-[b]-chromen-carboxylate-ethylester (CPCCOEt), and $\mathrm{D}(-)$-2-amino-5-phosphonopentanoate (D-AP5) were obtained from Tocris Bioscience. All other chemicals were purchased from Sigma.

Patch-clamp recording. For patch-clamp experiments, mice were decapitated, the brain was rapidly removed into ice-cold ACSF and transverse hippocampal slices $(300 \mu \mathrm{m})$ were made as described above. Cells were visualized using a Nikon Eclipse FN1 upright microscope equipped with infrared difference interference contrast optics and a water-immersion lens $(\times 60,1.0 \mathrm{NA}, \mathrm{Nikon})$. Somatic whole-cell current-clamp recordings were made in conjunction with a Multiclamp1B amplifier (Molecular Devices). Data were filtered at $10 \mathrm{kHz}$ and sampled at $50 \mathrm{kHz}$ with a Digidata $1322 \mathrm{~A}$ interface controlled by pClamp Software (Molecular Devices). Electrode resistance in the bath ranged from 2 to $3 \mathrm{M} \Omega$, and series resistance ranged from 13 to $25 \mathrm{M} \Omega$. The internal solution contained [in $\mathrm{mm}$ ]: 130 potassium gluconate, $20 \mathrm{KCl}, 10$ 4-(2-hydroxyethyl)-1-piperazineethanesulfonic acid, 0.16 ethylene glycol bis(2-aminoethylether)- $N, N, N^{\prime}, N^{\prime}$-tetraacetic acid, $2 \mathrm{Mg}$-ATP, $2 \mathrm{Na}$-ATP, 15 glucose (pH adjusted to 7.4 with $\mathrm{KOH}, 295 \mathrm{mOsmol}$ ). The extracellular ACSF was identical to that used in the mossy fiber LTP experiments $\left(32^{\circ} \mathrm{C}\right)$. A liquid junction potential of $14.8 \mathrm{mV}$ was determined for these solutions, and corrected such that the depicted potentials are $14.8 \mathrm{mV}$ more hyperpolarized than the measured potentials.

The passive membrane properties were calculated from long $(\geq 400$ $\mathrm{ms}$ ) subthreshold hyperpolarizing and depolarizing current pulses. Input resistance $\left(R_{\text {in }}\right)$ was determined as the slope of the peak membrane potential deflections elicited by injecting -50 to $+20 \mathrm{pA}$ current pulses. From the same voltage responses as above, the membrane time constant $(\tau)$ was determined from a single exponential fit to the charging phase. Action potential properties were determined from the first action potential elicited by just suprathreshold long duration depolarizing current pulses. Action potential threshold was the voltage at which the first derivative of the spike waveform exceeded $15 \mathrm{~V} \cdot \mathrm{s}^{-1}$. Action potential duration was measured at half action potential amplitude. From the same voltage responses, the fast afterhyperpolarization was deter-

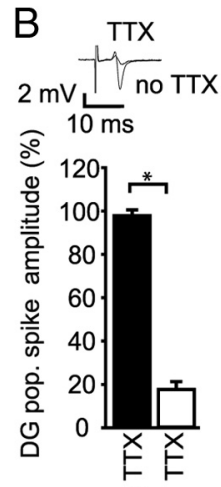

을
C no TTX + TTX
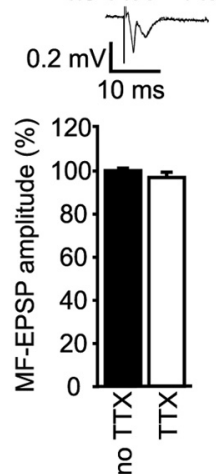

$\mathrm{F}$
$\mathrm{E}$

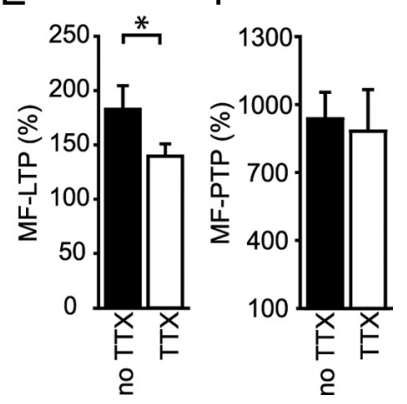

Figure 2. Important contribution of action potential firing at granule cell somata to mossy fiber long-term potentiation. $A$, Diagram of the experimental setup: We recorded antidromically stimulated MF-EPSPs by placing a recording electrode (a) and a stimulation electrode (b) in the CA3 stratum lucidum. TTX (10 $\mu \mathrm{M})$ was focally applied via two patch pipettes (d) to the dentate grits (DC) while the antidromic population spike was monitored with a recording electrode (c). The large arrow indicates the Aster a could be measured. This MF-LTP was reduced by the puff application (indicated by two arrows) of TIX (open Insets show representative sample traces obtained at the time points indicated by the lowercase letters. in the level of MF-LTP following fol TTX application (open bar) compard to recordings in which puff application was onith (filled bar) 60 min after tetanization. $\boldsymbol{F}$, Similar levels of MF post-tetanic potentiation were obtained with (open bar) and without (filled bar) an antecedent TTX application.

mined as the lowest membrane potential reached within $5 \mathrm{~ms}$ following the peak of the action potential. Afterdepolarization amplitude was determined as the peak membrane potential reached $>5 \mathrm{~ms}$ following the peak of the action potential elicited by brief ( $4 \mathrm{~ms}$ ) depolarizing current pulses.

Imaging experiments. Imaging experiments were performed with a two-photon laser scanning microscope (Ultima, Prairie Technologies). Laser polarization was controlled with a $\lambda / 2$ plate (Thorlabs). Second harmonic (SH) radiation at $485 \mathrm{~nm}$ was excited with a pulsed Ti:Sa laser (Chameleon, Coherent) set to $970 \mathrm{~nm}$ through a $20 \times$ water-immersion objective (NA 0.95, Olympus). SH radiation was collected in a forward direction with a condenser (NA 0.8, Olympus) in Köhler position and filtered with a $485 / 20$ bandpass (Semrock). The power density at the sample plane was $\sim 5.5 \mathrm{MW} / \mathrm{cm}^{2}$ for a focal spot diameter of $650 \mathrm{~nm}$ and a laser power of $70 \mathrm{~mW}$. Images were analyzed using ImageJ and Igor Pro (Wavemetrics).

Statistical analyses. All statistical comparisons were calculated with the R statistical package (http://www.R-project.org) or GraphPad Prism (Statcon). Two sorts of analyses were performed. First, when a comparison was between the means of two groups with equal variance (as assessed with an $F$ test), a Student's $t$ test was used. Second, when the comparison was between the means of two groups with unequal variance as assessed with an $F$ test, Welch's $t$ tests were performed. 

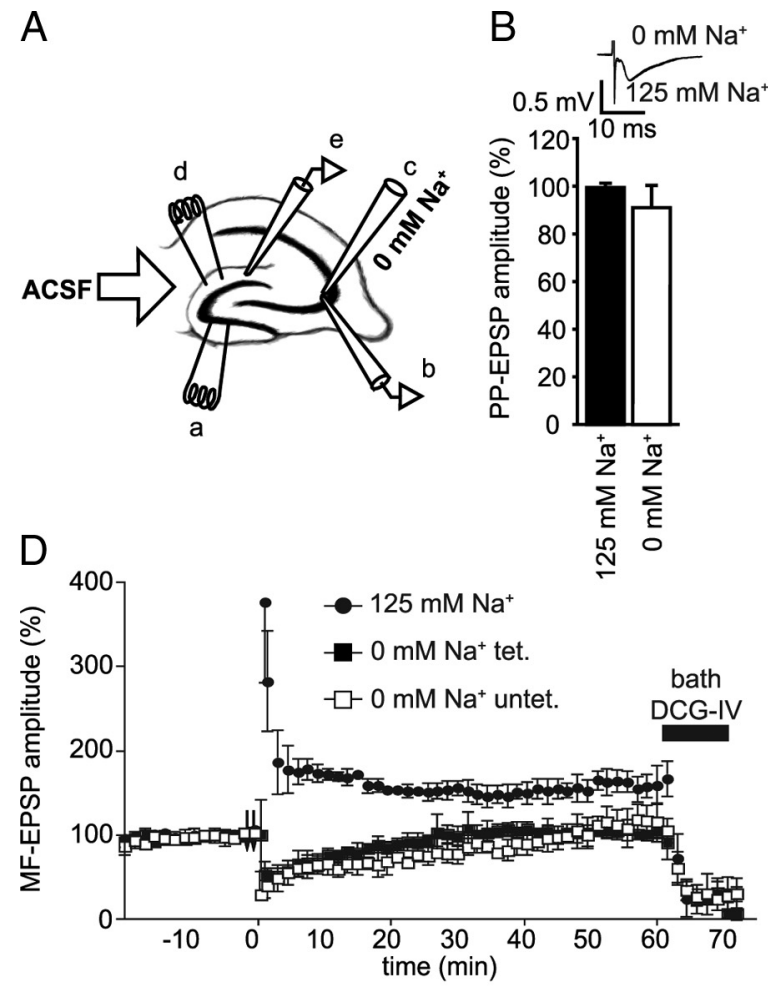
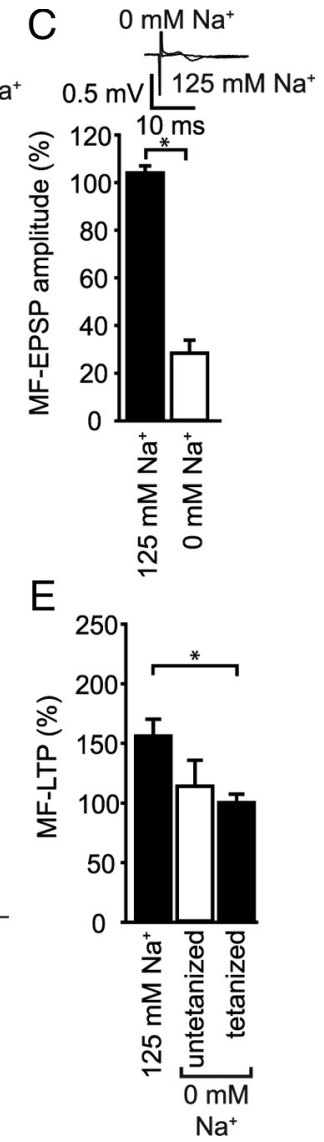

Figure 3. Contribution of action potential firing at mossy fiber terminals to the induction of long-term potentiation. $A$, Diagram of the experimental setup: Recording of MF-EPSPs was performed by stimulation of dentate gyrus (DG) granule cell somata (a). A recording electrode was placed in the stratum lucidum of area $\mathrm{CA3}$ (b). $\mathrm{ACSF}$ or $\mathrm{Na}^{+}$-free solution was focally applied to the $\mathrm{CA} 3$ stratum lucidum (c) near the site of the recording electrode at position $b$. To ensure that the focal applications were restricted to the CA3 region, we monitored PP-EPSPs in the DG ( $d$ and e). The large arrow illustrates the direction of the ACSF flow in the recording chamber. $\boldsymbol{B}$, Puff application of $\mathrm{Na}^{+}$-free solution (open bar) or ACSF (filled bar) to the CA3 stratum lucidum had no impact on the amplitude of PP-EPSPs. C, Focal application of $\mathrm{Na}^{+}$-free solution (open bar) to the $\mathrm{CA} 3$ dramatically reduced the amplitudes of MF-EPSPs when compared to the application of ACSF (filled bar). D, Time course of the MF-EPSP amplitudes before and after tetanization. A robust MF-LTP could be established after puff application (indicated by the two arrows) of ACSF (filled circles), but was completely abolished by focal application of $\mathrm{Na}^{+}$-free solution (filled squares) during the tetanus. Focal application of $\mathrm{Na}^{+}-$ free solution to untetanized controls (open squares) demonstrated that the effect of puffapplying $\mathrm{Na}^{+}$-free solution was reversible within $1 \mathrm{~h}$. Insets show representative sample traces obtained at the time points indicated by the lowercase letters. $E$, Summary of the magnitude of MF-LTP 60 min after the tetanus in the experiments presented in $\boldsymbol{D}$. Asterisk indicates significant $(p<0.05)$ differences in the levels of LTP. There was a complete loss of MF-LTP ( $60 \mathrm{~min}$ after tetanus) following the application of $\mathrm{Na}^{+}$-free solution to the MF terminals (filled bar) compared to sham application of ACSF (open bar) and untetanized controls with focal application of ACSF (filled bar).

\section{Results}

\section{Activation of postsynaptic CA3 pyramidal cells is not necessary for MF-LTP}

Does MF-LTP require the activation of postsynaptic glutamate receptors? Many (Castillo et al., 1994; Nicoll and Malenka, 1995; Mellor and Nicoll, 2001), but not all (Yeckel et al., 1999), studies have found that it does not. Because this was a critical question for the bulk of our experiments, we first performed a series of experiments to verify that MF-LTP does not require activation of postsynaptic glutamate receptors under our experimental conditions.

Under control conditions, tetanization of the MFs induced LTP of the MF-EPSPs that was $176.1 \pm 5.4 \%$ of the baseline response $2 \mathrm{~h}$ after tetanus $(n=5)$ (Fig. $1 A)$. Next, we tested whether blocking AMPA-type glutamate receptors during LTP induction would diminish the magnitude of MF-LTP: We tetanized MFs during a bath application of the AMPA/kainate-type

glutamate receptor antagonist CNQX (25 $\mu \mathrm{M})$ (Fig. $1 B$ ). The bath application of CNQX almost completely blocked MFEPSPs, and, following a $2 \mathrm{~h}$ washout period, a large potentiation (Fig. $1 B, E$ ) was observed in tetanized $(n=6)$ (filled circles in Fig. $1 B$ ) versus untetanized control $(n=4)$ (empty circles in Fig. $1 B$ ) slices that had received an equivalent bath application of CNQX $\left(t_{(8)}=16.9, p=8 \times\right.$ $\left.10^{-8}\right)$. It has been suggested that the activation of postsynaptic metabotropic glutamate receptors (mGluRs) is essential for the induction of MF-LTP (Yeckel et al., 1999). We therefore performed additional experiments in which we bath applied antagonists of mGluR1 and mGluR5 (10 $\mu \mathrm{M}$ MPEP and $100 \mu \mathrm{M}$ CPCCOEt) together with $25 \mu \mathrm{M}$ CNQX. Combined blockade of ionotropic glutamate receptors and mGluR1/5 receptors did not eliminate MF-LTP $(n=6)$ (filled circles in Fig. $1 C$ ) when compared to untetanized control slices (empty circles in Fig. 1C) $\left(n=3, t_{(7)}=10.3, p=9 \times 10^{-6}\right)$. Thus, activation of postsynaptic AMPA/kainatetype glutamate receptors and mGluR1/5 receptors is not required for MF-LTP induction under our experimental conditions. Conversely, blocking voltage-gated $\mathrm{Ca}^{2+}$ channels during MF-LTP induction with $\mathrm{Co}^{2+}(2 \mathrm{mM})$ resulted in a complete loss of MF-LTP $(n=5)$ (filled circles in Fig. $1 D)$ compared to untetanized controls (empty circles in Fig. $1 D)\left(n=5, t_{(8)}=\right.$ $1.5, p=0.09$ ).

The data from this first set of experiments support the view that the induction of MF-LTP requires presynaptic firing and concomitant $\mathrm{Ca}^{2+}$ influx via voltage-gated $\mathrm{Ca}^{2+}$ channels (Castillo et al., 1994; Nicoll and Malenka, 1995; Mellor and Nicoll, 2001). This first set of experiments relied on bath perfusion of pharmacological antagonists. Accordingly, these data do not allow one to discriminate the role of the soma versus axon terminals of dentate granule cells.

\section{Action potential firing at granule cell somata contributes to MF-LTP induction}

In view of that deficiency, we next performed a set of experiments that assessed the effects on MF-LTP of blocking action potentials at the granule cell somata, but not the MF terminals. To achieve such a selective blockade, we focally applied TTX to both the inferior and superior blades of the dentate gyrus using focal pressure-induced ("puff") applications from two patch pipettes (pipettes containing $10 \mu \mathrm{M}$ TTX and labeled with a lowercase $\mathrm{d}$ in Fig. $2 \mathrm{~A}$ ). During the puff application of TTX, antidromic population spikes were elicited with a stimulation electrode positioned in the CA3 region and recorded from the granule cell layer (pipettes labeled with a lowercase $b$ and e, respectively, in Fig. 2A). After focal TTX application to the dentate gyrus, population spikes were significantly reduced in amplitude (to $17.7 \pm 3.6 \%$ of 
baseline levels; $n=5$ ) (open bar in Fig. $2 B)$ relative to slices that did not receive $\operatorname{TTX}\left(t_{(9)}=18.8, p=1.0 \times 10^{-8}\right)$.The magnitude of the MF-EPSPs was unaffected by the focal TTX applications, confirming that the focal TTX applications did not reduce the $\mathrm{Na}^{+}$currents at MF terminals ( $97.4 \pm 2.3 \%$ of baseline levels, $n=5$ ) (open bar in Fig. 2C). The antidromic population spikes, as well as the MF-EPSPs, were stable in slices in which all pipettes were placed as above, but puff application was omitted $(n=6)$ (filled bars in Fig. $2 B, C$ ). These data demonstrate that focal TTX application can block action potentials at the granule cell somata while leaving action potentials and neurotransmitter release at the MF terminals unaffected.

When focal application of TTX was omitted, we obtained an initial posttetanic potentiation (PTP) (filled bar in Fig. $2 F$ ), with a subsequent expression of MF-LTP that was comparable to control conditions in Figure 1 A $(189 \pm 20 \%$ of baseline levels $1 \mathrm{~h}$ after tetanization; $n=$ 6) (filled circles in Fig. 2D). In contrast, in those slices in which somatic $\mathrm{Na}^{+}$channels and somatic spiking were blocked with the focal application of TTX, the level of MF-LTP $1 \mathrm{~h}$ after tetanization was significantly reduced $(140.0 \pm 11.0 \% ; n=5$, $\left.t_{(9)}=2.0, p=0.04\right)$ (empty circles in Fig. $2 D$; for comparison, see Fig. $2 E$ ), even though the post-tetanic potentiation was comparable (Fig. $2 F$ ).

\section{Action potential firing at MF terminals is necessary for MF-LTP induction}

We next asked whether action potential firing at MF axon terminals is required for LTP induction. Because the effects of puff applying TTX proved difficult to wash out, we used puff applications to the stratum lucidum of an ACSF-based solution in which $\mathrm{NaCl}$ had been replaced with choline chloride (lowercase $\mathrm{c}$ in Fig. 3A). MFs were stimulated with a stimulation electrode positioned in the dentate gyrus granule cell layer (lowercase a in Fig. 3A). Puff applications of $\mathrm{Na}^{+}$-free ACSF caused a significant reversible reduction of MF-EPSPs to $28.4 \pm 5.3 \%$ of baseline levels $(n=4)$ (open bar in Fig. $3 C)\left(t_{(7)}=13.4, p=2 \times 10^{-6}\right)$. These applications did not affect EPSPs at the perforant path-granule cell synapse (91.2 \pm $9.2 \% ; n=6$ ) (open bar in Fig. 3B; the positions of the recording and stimulation electrodes are indicated with a lowercase e and d, respectively, in Fig. $3 A$ ), confirming that the application of the $\mathrm{Na}^{+}$-free ACSF was restricted to the CA3 region.

Puff applications of ACSF did not alter either MF-EPSPs $(104.4 \pm 2.8 \% ; n=5)$ (filled bar in Fig. $3 C$ ) or PP-EPSPs (99.6 \pm 1.7; $n=6$ ) (filled bar in Fig. 3B). Under control conditions (i.e., puff application of normal ACSF), stable MF-LTP could be induced by tetanization $(157.3 \pm 13.3 \% ; n=5$ ) (filled circles in Fig. $3 D$; left filled bar in Fig. 3E). In contrast, MF-LTP induction was impaired when $\mathrm{Na}^{+}$-free ACSF was puff applied during tetaniza-
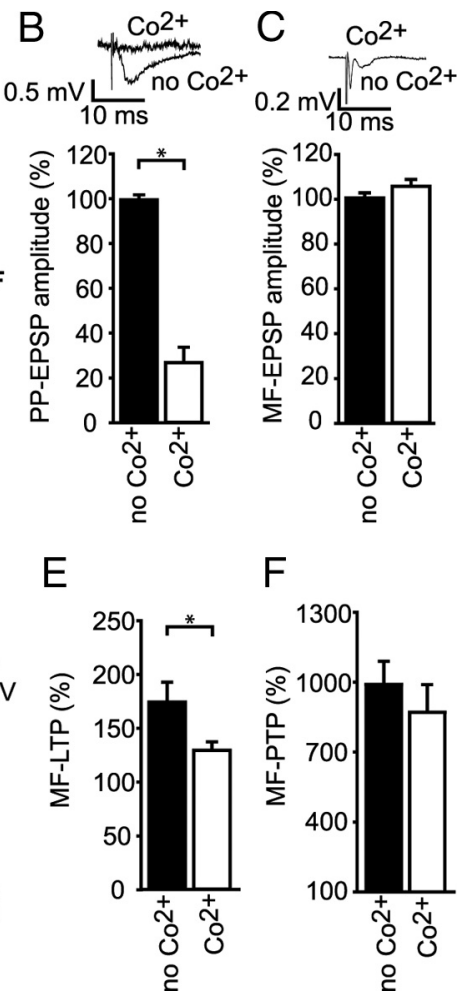

Figure 4. Contribution of $\mathrm{Ca}^{2+}$ influx at granule cell somata to the induction of mossy fiber long-term potentiation. $\boldsymbol{A}$, Diagram of the experimental setup: We focally applied $\mathrm{Co}^{2+}(5 \mathrm{~mm})$ to the dentate gyrus (DG) granule cell layer (a). We also elicited and recorded PP-EPSPs ( $c$ and b, respectively) to confirm the effectiveness of those applications. MF-EPSPs were obtained with a the direction of the ACSF flow in the chamber. $\boldsymbol{B}$, Placement of the pipettes a without puff application (filled bar) had no influence PP-EPSP, but the puff application of $\mathrm{C}^{2+}$ (open bar) dramatically reduced the magnitude of PP-EPSPs. C, MF-EPSPs were left D Time course of the amplitude of the EPSPs recorded at the MF pathway. Recordings in which no puff application was (filled circles) during the tetanus (time point zero) produced a stable LTP. By contrast, the levels of MF-LTP were strongly reduced by a focal application of $\mathrm{Co}^{2+}$ (open circles). Insets show representative sample traces from the time points indicated by

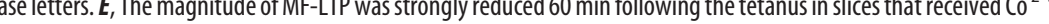
differences $(p<0.05)$. F Quantification of the MF PTP from the experiments illustrated in D showed that there were equivalent levels of PTP following tetanization in slices that received $\mathrm{C}^{2+}$ puff applications (open bar) versus those that did not (filled bar).

tion $\left(101.3 \pm 6.2 \% ; n=4 ; t_{(7)}=3.5, p=0.005\right)$ (filled squares in Fig. 3D; right filled bar in Fig. $3 E$ ). Control experiments in which $\mathrm{Na}^{+}$-free ACSF was applied without tetanization revealed that the effects of the focal application were completely reversible within $1 \mathrm{~h}(115 \pm 21.1 \%, n=4)$ (open squares in Fig. 3D; open bar in Fig. 3E).

\section{$\mathrm{Ca}^{2+}$ influx at granule cell somata contributes to MF-LTP induction}

Collectively, these results indicate that action potential firing at both granule cell somata and MF terminals is essential for MFLTP induction. We next examined whether blocking action potential-dependent $\mathrm{Ca}^{2+}$ influx only at the granule cell somata would likewise affect MF-LTP induction. We puff applied $5 \mathrm{~mm}$ $\mathrm{Co}^{2+}$ to the granule cell layer via two patch pipettes during tetanization (pipettes labeled with a lowercase a in Fig. 4A). Puff application of $\mathrm{Co}^{2+}$ strongly and reversibly reduced PP-EPSPs (block to $27.0 \pm 6.2 \%$, and recovery to $95 \pm 8 \%$ of baseline amplitude; $n=6 ; t_{(6.2)}=11.2, p=1.0 \times 10^{-5}$ ) (open bar in Fig. $4 B$ ), while leaving MF-EPSPs unaffected (104.6 $\pm 3.2 \%$ of baseline amplitude; $n=6$ ) (open bar in Fig. $4 C$ ). In control experiments, placing all electrodes but omitting the puff application of 

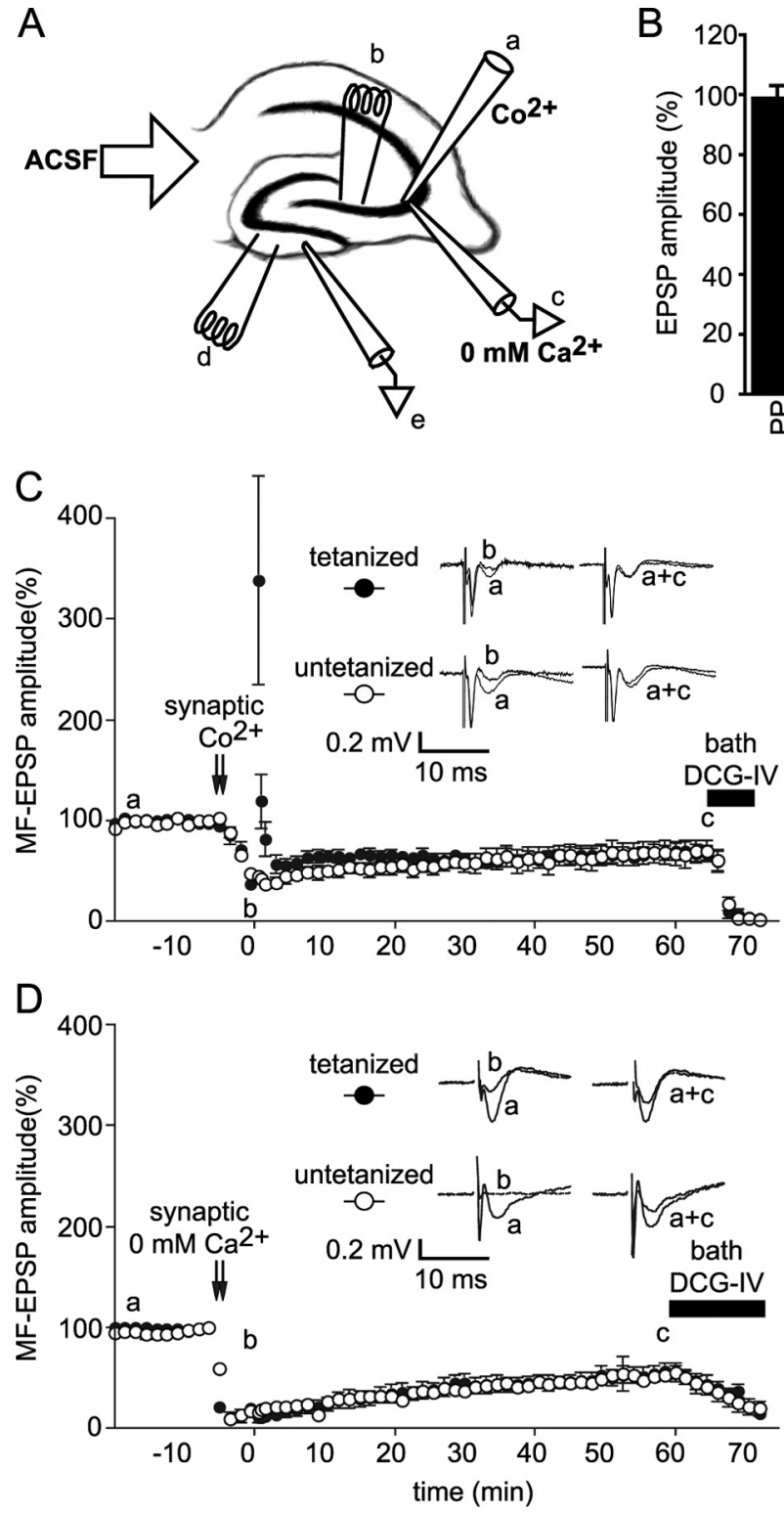

Figure 5. Contribution of $\mathrm{Ca}^{2+}$ influx at mossy fiber terminals to the induction of long-term potentiation. $A$, Diagram of the experimental setup: $\mathrm{CO}^{2+}(5 \mathrm{~mm})$ was focally applied to MF synapses (a). MF-EPSPs were obtained with a stimulation electrode (b) and a recording electrode (c) that were placed in the $\mathrm{CA} 3$ stratum lucidum. To confirm that the $\mathrm{C}^{2+}$ applications had no influence on $\mathrm{Ca}^{2+}$ influx at the dentate gyrus (DG) granule cell somata, we also elicited and recorded PP-EPSPs (d and e, respectively). $\boldsymbol{B}$, Focal application of $\mathrm{C}^{2+}$ did not reduce the amplitude of PP-EPSPS, while MF-EPSPs were strongly reduced, confirming that the focal application of $\mathrm{CO}^{2+}$ was restricted to the $\mathrm{CA}$. Representative traces are shown in the insets. $C$, Time course of average MF-EPSP amplitudes of tetanized (filled circles) and untetanized (open circles) slices after $\mathrm{C}^{2+}$ application (time point indicated by black arrows). Tetanization was performed at time point zero. Although the effects of focal $\mathrm{C}^{2+}$ applications (two arrows) were not completely reversible within the $1 \mathrm{~h}$ after tetanus, the comparison of tetanized and untetanized slices revealed an absence of MF-LTP following synaptic puff applications of $\mathrm{C}^{2+}$. Insets show representative sample traces from the time points indicated by the lowercase letters. $\boldsymbol{D}$, Focal application of $\mathrm{Ca}^{2+}$-free solution. Application was done via the field potential recording electrode (indicated in $\boldsymbol{A}$, see Materials and Methods). Time course of average MF-EPSP amplitudes in tetanized (filled circles) and untetanized (open circles) slices. $\boldsymbol{E}$, Summary of the amount of MF-LTP in the experiments illustrated in $\boldsymbol{C}$. Tetanization of slices that received synaptic applications of $\mathrm{Co}^{2+}$ or $\mathrm{Ca}^{2+}$-free ACSF (filled bar) failed to produce any MF-LTP relative to untetanized (open bars) slices.

$\mathrm{Co}^{2+}$ did not significantly alter PP- or MF-EPSPs $(99.5 \pm 1.8 \%$ and $101.0 \pm 2.2 \%$, respectively, $n=6$ and 6 ) (filled bars in Fig. $4 B, C)$. These data indicate that the focal application of $\mathrm{Co}^{2+}$ can effectively block $\mathrm{Ca}^{2+}$ channels in the dentate gyrus without significantly affecting $\mathrm{Ca}^{2+}$ channels in the $\mathrm{CA} 3$ region.

Under control conditions, tetanization induced a PTP (truncated in Fig. $4 D$, see filled bar in Fig. $4 F$ ), with a subsequent expression of MF-LTP $1 \mathrm{~h}$ after the tetanization (175.4 $\pm 18.3 \%$; $n=6)$ (filled circles in Fig. $4 D$; filled bars in Fig. $4 E$ ). In slices in which $\mathrm{Co}^{2+}$ was focally applied to the granule cell layer during LTP induction, PTP levels were nearly identical (Fig. $4 F$ ), but the levels of MF-LTP $1 \mathrm{~h}$ after tetanization were significantly reduced $\left(130.2 \pm 7.7 \% ; n=5 ; t_{(9)}=2.1, p=0.03\right)$ (empty circles in Fig. $4 D$; for a comparison, see Fig. 4E).

\section{Importance of $\mathrm{Ca}^{2+}$ influx at MF terminals for LTP induction}

We next examined whether blocking action potential-dependent $\mathrm{Ca}^{2+}$ influx only at the MF terminals would affect MFLTP induction. We puff applied $5 \mathrm{~mm}$ $\mathrm{Co}^{2+}$ to the stratum lucidum of the CA3 region (pipette labeled with a lowercase a in Fig. 5A)-close to the MF-EPSP recording electrode (pipette labeled with a lowercase $\mathrm{c}$ in Fig. 5A). These focal applications of $\mathrm{Co}^{2+}$ potently reduced MFEPSP amplitude to $41.9 \pm 3.2 \%$ of baseline levels $(n=12)$ (Fig. $5 B$; see also Fig. $5 C$ ). PP-EPSPs were not affected by these focal $\mathrm{Co}^{2+}$ applications (99.2 \pm $4.1 \% ; n=4$ ) (Fig. $5 B$ ), demonstrating that the effects of the $\mathrm{Co}^{2+}$ applications were limited to the $\mathrm{CA} 3$ region. The reduction of MF-EPSPs following $\mathrm{Co}^{2+}$ puff application was not reversible. However, comparing slices tetanized in the presence of focal $\mathrm{Co}^{2+}(n=7)$ to untetanized slices subjected to focal $\mathrm{Co}^{2+}$ applications $(n=5)$ revealed the absence of MF-LTP following synaptic applications of $\mathrm{Co}^{2+}$ [Fig. 5C; tetanized, $67.8 \pm 8.3 \%$, $n=7$ (filled bar in Fig. 5E); untetanized, $67.6 \pm 11.2 \%, n=5$ (open bar in Fig. $5 E)$ ]. In view of the limited reversibility of the focal $\mathrm{Co}^{2+}$ application, we locally reduced mossy fiber terminal $\mathrm{Ca}^{2+}$ influx by an alternative approach. We introduced nominally $\mathrm{Ca}^{2+}$ free extracellular solution directly into the MF recording electrode and ejected this solution locally by applying limited pressure $(30-40$ mbar) to the recording electrode. This form of application led to a profound reduction of MF-EPSPs to $<10 \%$ (see Fig. $5 D$ ) that was not observed in control experiments in which the pipette contained normal ACSF (not shown). In these experiments, similar to the focal applications of $\mathrm{Co}^{2+}$, full recovery of MF-EPSPs could not be obtained. Nevertheless, also in these experiments, comparison of tetanized to untetanized slices did not reveal any evidence for MF potentiation (tetanized, $54.6 \pm 8.4, n=6$, untetanized $54.7 \pm 17.3, n=$ 6) (Fig. 5E). These results are consistent with the idea that MFLTP does not occur in the absence of MF terminal $\mathrm{Ca}^{2+}$ influx. It should be noted, however, that these experiments also indicate 
that removing $\mathrm{Ca}^{2+}$ influx from mossy fiber terminals appears to have long-term depressing effects. Caution should therefore be exercised in the interpretation of this particular set of results.

\section{Disrupting axonal microtubules or protein synthesis impairs the ability to sustain MF-LTP}

The data so far indicate that action potential firing and $\mathrm{Ca}^{2+}$ influx into the somatic compartment of granule cells are required during tetanization for the induction of stable MF-LTP. This requirement is consistent with the notion that signaling between the granule cell soma and the MF terminal is necessary for stable MF-LTP. Accordingly, we next explored the contributions of fast axonal transport to MF-LTP by incubating hippocampal slices with the microtubule-depolymerizing agent nocodazole. To confirm that nocodazole disrupted the microtubule network, we measured the optical SH signal generated by MF-axons (Dombeck et al., 2003; Kwan et al., 2008) during a bath application of $25 \mu \mathrm{M}$ nocodazole (Fig. $6 A, B)$ with a two-photon microscope. During the $1 \mathrm{~h}$ applications of nocodazole, there was a strong reduction of the $\mathrm{SH}$ signal. To ensure that nocodazole application did not lead to dramatic changes in the properties of hippocampal neurons, we performed patch-clamp recordings from visually identified CA3 pyramidal neurons and assessed their firing properties (see Materials and Methods). Properties of CA3 cells, shown in Table 1, were closely comparable with those previously described in patch-clamp recordings (Brown and Randall, 2009), and for most parameters revealed no differences in action potential generation between slices preincubated with nocodazole and control slices. There was, however, a significant $5 \mathrm{mV}$ hyperpolarizing shift in the action potential threshold (see Table 1 and supplemental Fig. 1, available at www. jneurosci.org as supplemental material).

Having confirmed the disruption of the microtubule network with nocodazole, we next recorded MF-EPSPs in slices that were incubated for at least $1 \mathrm{~h}$ with $25 \mu \mathrm{M}$ nocodazole $(n=5)$ and untreated control slices $(n=5)$ (Fig. $6 C, D)$. In all of these experiments, $25 \mu \mathrm{M}$ D-APV was present during the tetanization. At time points $>15$ min following tetanization, MF-EPSP amplitudes in the nocodazole-treated slices declined, whereas in control slices, MFLTP was stable after $1 \mathrm{~h}$ of recording (Fig. 6C). The amount of LTP $1 \mathrm{~h}$ after tetanization was significantly reduced in the presence of nocodazole $(112.1 \pm 9.3 \%$ ) (open bar in Fig. $6 E$ ) relative to control $\left(149.4 \pm 5.6 \%, t_{(8)}=3.43, p=0.005\right)$ (filled bar in Fig. $6 E)$. At the same time, paired-pulse facilitation was unaltered by nocodazole exposure $(25 \mu \mathrm{M}, 274 \pm 24$ vs $277 \pm 19 \%$ facilitation
B

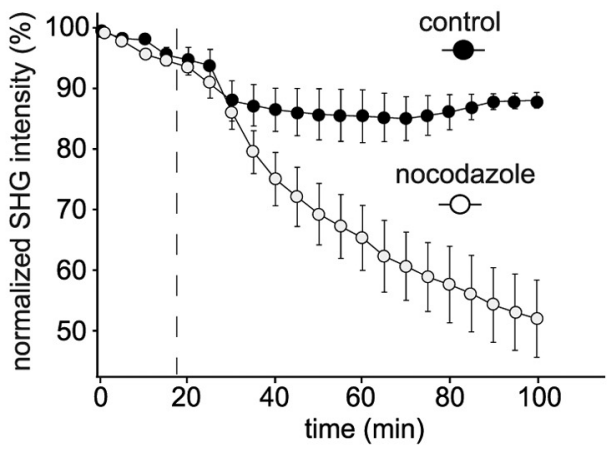

E

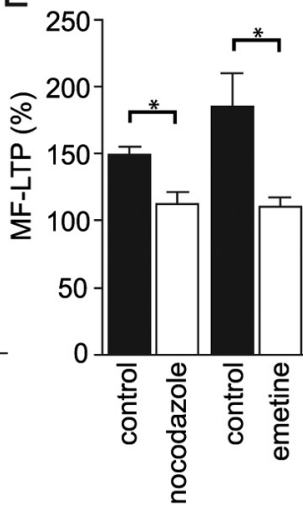

Figure 6. Disrupting fast axonal transport or protein synthesis impairs the maintenance of mossy fiber long-term potentiation. $\boldsymbol{A}$, Nocodazole disrupts microtubule structures in acute slices. Top, Representative SH signal from a hippocampal slice of a 27-d-old mouse. The image is a mosaic of $z$-projected image stacks. Bottom, Enlarged view of the infrapyramidal MF bundle. $\boldsymbol{B}$, Time course of the $\mathrm{SH}$ signal in the area shown in the lower part of $\boldsymbol{A}$. Dashed line indicates the beginning of the nocodazole ( $25 \mu \mathrm{M})$ application. 列 emetine impairs stable MF-LTP. Time course of MF-EPSPs after tetanization is shown for slices preincubated for at least $1 \mathrm{~h}$ with significant reduction of MF-LTP following treatment with nocodazole or emetine. Asterisks indicate significant $(p<0.05)$ differences in the amount of MF-LTP 60 min after tetanization.

in control and nocodazole incubated slices, respectively, $n=8$ for both groups). Baseline MF-EPSP size was also unaltered in a set of experiments in which we washed in $10 \mu \mathrm{M}$ nocodazole for at least $30 \mathrm{~min}$ (MF-EPSP amplitude after application of nocodazole $107 \pm 7 \%$ of baseline MF-EPSP amplitude). These data indicate that intact axonal transport via microtubules is required for the expression of stable MF-LTP, but not for short-term synaptic plasticity.

The most straightforward explanation for the present set of results is that somatic activity triggers somatic synthesis of proteins, which are then transported to MF terminals and contribute to MF-LTP stabilization. We therefore tested whether protein 
Table 1. Effects of $25 \mu \mathrm{m}$ nocodazole on passive and active properties of CA3 neurons in hippocampal slices

\begin{tabular}{lcc}
\hline & Control & Nocodazole treated \\
\hline$R_{\text {in }}(\mathrm{M} \Omega)$ & $164 \pm 80$ & $125 \pm 47$ \\
$\tau(\mathrm{ms})$ & $61 \pm 21$ & $56 \pm 21$ \\
$C_{\mathrm{m}}(\mathrm{pF})$ & $424 \pm 209$ & $403 \pm 158$ \\
$V_{\mathrm{m}}(\mathrm{mV})$ & $-76 \pm 5$ & $-78 \pm 7$ \\
AP peak $(\mathrm{mV})$ & $26 \pm 13$ & $24 \pm 10$ \\
AP threshold $(\mathrm{mV})$ & $-58 \pm 5$ & $-63 \pm 4^{* *}$ \\
AP duration $(\mathrm{ms})$ & $0.79 \pm 0.21$ & $0.77 \pm 0.14$ \\
Fast AHP $(\mathrm{mV})$ & $-64 \pm 8.3$ & $-69 \pm 3.7$ \\
ADP $(\mathrm{mV})$ & $6.0 \pm 4.7$ & $4.9 \pm 2.4$ \\
$n$ & 12 & 13
\end{tabular}

Data are presented as mean values $\pm S D$ and $n$ values represent the number of CA3 cells from which data were obtained. ${ }^{* *} p<0.01$ compared to the respective control values paired using the paired Student's two-tailed $t$ test. $R_{\mathrm{in},}$, Input resistance; $\tau$, membrane time constant; $C_{m}$, membrane capacitance; $V_{m}$, resting membrane potential; $A P$, action potential; AP duration, action potential duration at half-maximal amplitude; fast AHP, fast spike afterhyperpolarization; ADP, spike afterdepolarization.

synthesis is required for stable MF-LTP by preincubation of hippocampal slices with the translation inhibitor emetine $(25 \mu \mathrm{M}, 60$ min). In emetine-treated slices, MF-LTP was not maintained (MF-EPSPs after 1 h $110.9 \pm 6.7 \%$ of baseline MF-EPSP, $n=6$ ), in contrast to interleaved control slices in which stable MF-LTP was observed ( $185 \pm 25 \%$ of baseline MF-EPSP, $n=5, p=0.018$ ) (Fig. 6D,E).

\section{Discussion}

We assessed the contributions of activity within the granule cell somata and the MF terminals to MF-LTP. There were three major findings. First, we showed that action potentials at both the dentate granule cell soma and at the MF boutons are necessary for MF-LTP. Second, we found that blocking $\mathrm{Ca}^{2+}$ channels only at the dentate granule cell soma is sufficient to disrupt MF-LTP. Finally, we demonstrated that the disruption of fast axonal transport mechanisms or protein synthesis can disrupt MF-LTP. Collectively, these data suggest that - in addition to $\mathrm{Ca}^{2+}$ influx into MF terminals - the induction of MF synaptic plasticity also requires action potential-dependent $\mathrm{Ca}^{2+}$ signaling at granule cell somata and fast axonal transport along MFs.

Tetanic stimulation of the MF pathway produces robust LTP of the MF-CA3 synapse. During MF tetanization, strong activation of postsynaptic NMDA-type receptors, AMPA-type receptors, or mGluRs undoubtedly occurs. However, blocking one or a combination of these receptor types does not reduce MF-LTP (Castillo et al., 1994; Nicoll and Malenka, 1995; Mellor and Nicoll, 2001; and the present study). In addition, introduction of high concentrations of the high-affinity $\mathrm{Ca}^{2+}$ buffer BAPTA into CA3 neurons does not block MF-LTP (Mellor and Nicoll, 2001) (but see Yeckel et al., 1999). This has led to the view that MF-LTP induction is dependent mainly on $\mathrm{Ca}^{2+}$ influx into the presynaptic granule cells. The results of the present set of experiments confirm that presynaptic voltage-gated $\mathrm{Ca}^{2+}$ channels mediate the $\mathrm{Ca}^{2+}$ influx required for MF-LTP induction: Blockade of ionotropic glutamate receptors and/or mGluRs during LTP induction failed to influence MF-LTP expression, whereas blockade of voltage-gated $\mathrm{Ca}^{2+}$ channels did reduce MF-LTP.

The dependence of MF-LTP on voltage-gated $\mathrm{Ca}^{2+}$ channels has triggered interest into which channel subtypes are involved. Prior studies have elaborated the contribution of specific subtypes of $\mathrm{Ca}^{2+}$ channels to synaptic transmission and LTP at MF terminals (Castillo et al., 1994; Dietrich et al., 2003). These investigations have assumed that the $\mathrm{Ca}^{2+}$ influx relevant for MF-LTP occurs at presynaptic terminals. However, it has remained un- clear whether this is indeed the case. In addition to MF terminals, action potential-dependent $\mathrm{Ca}^{2+}$ entry at granule cell somata might also be necessary for the induction of stable MF-LTP. To address this issue, we first used focal drug applications to block action potential firing or $\mathrm{Ca}^{2+}$ influx at dentate granule cell somata but not at MF terminals during MF-LTP induction. These experiments unequivocally show that spiking and $\mathrm{Ca}^{2+}$ influx at dentate granule cell somata is required for the induction of stable MF-LTP. When $\mathrm{Ca}^{2+}$ influx or spiking at granule cell somata was prevented, tetanization caused a post-tetanic potentiation that was indistinguishable from the control situation. This potentiation subsequently decayed over 20-30 min. This suggests that MF terminals contain the machinery to generate a PTP and an early phase of LTP, but require the soma for maintenance of LTP over longer time periods. This idea was also put forward in a study demonstrating that MF-LTP is decremental if MFs are transected, or if transcription or translation blockers are applied (Calixto et al., 2003). It should be noted, however, that transection approaches are hard to interpret, because axonal transection can cause prolonged high-frequency activity in neurons, coupled with strong increases in intraneuronal $\mathrm{Ca}^{2+}$ (see e.g., Mandolesi et al., 2004; Gitler and Spira, 1998; Ziv and Spira, 1997). This issue is particularly relevant for mossy fiber LTP, because it can be induced by high-frequency presynaptic activity alone.

If activity at the somatic compartment of granule cells is important for the later stages of LTP, we reasoned that $\mathrm{Ca}^{2+}$ influx restricted to the soma might be capable of LTP induction. We tested this notion by selectively blocking either action potential firing or $\mathrm{Ca}^{2+}$ influx at MF terminals without affecting their somata within the dentate gyrus. These experiments revealed that MF-LTP is absent when action potential firing at MF terminals is blocked. The results of blocking $\mathrm{Ca}^{2+}$ influx only at mossy fiber terminals are consistent with a role of local $\mathrm{Ca}^{2+}$ influx into MF terminals for MF-LTP. However, because blocking $\mathrm{Ca}^{2+}$ influx had partially irreversible effects, the interpretation of these experiments is equivocal. Nevertheless, given that we show that action potentials at mossy fibers are required for stable MF-LTP, it seems likely that the action potential associated $\mathrm{Ca}^{2+}$ influx into MF terminals is also relevant for MF-LTP. Thus, stable MF-LTP requires activity-dependent $\mathrm{Ca}^{2+}$ influx through voltage-gated $\mathrm{Ca}^{2+}$ channels at the somatic compartment and likely also at the MF terminal.

Our results suggest that somatic activity is required to trigger protein synthesis at the soma. Newly synthesized proteins are then transported to MF terminals and contribute to MF-LTP stabilization. We therefore disrupted fast, microtubule-dependent transport by applying the microtubule-depolymerizing agent nocodazole. We verified the disaggregation of axonal microtubules by monitoring the $\mathrm{SH}$ radiation obtained when hippocampal slices were illuminated with a pulsed infrared laser. Microtubules generate a strong SH signal due to their intrinsic optical asymmetry (Dombeck et al., 2003; Kwan et al., 2008). Disrupting microtubules, and thereby axonal transport, impaired the ability of MFs to sustain LTP after tetanization. The inability to sustain LTP was similar to the observations after somatic application of $\mathrm{Na}^{+}$or $\mathrm{Ca}^{2+}$ channel blockers, or inhibition of protein synthesis. It should be noted that microtubule depolymerization may also have additional contaminating effects, such as the small but significant hyperpolarizing shift in action potential threshold. This effect is unlikely to explain why MF-LTP is decremental after nocodazole preincubation. In addition, baseline mossy fiber synaptic transmission and short-term plasticity were unaltered (this study), and LTP at other synapses such 
as the Schaffer collateral-CA1 synapse has been shown to be unaffected by microtubule disruption (Vickers and Wyllie, 2007).

What is the current evidence supporting activity-dependent synthesis of presynaptic proteins and transport to presynaptic terminals? A number of studies have demonstrated that the abundance of presynaptic proteins can be modified by activity. For instance, LTP induction in the dentate gyrus in vivo causes upregulation of syntaxin $1 \mathrm{~b}$ and synapsin I mRNA and protein in the MF pathway, and an increase of glutamate release from MF terminals (Hicks et al., 1997; Helme-Guizon et al., 1998). In addition, an increase in synapsin, synaptotagmin, and synaptophysin levels has been observed in the dentate gyrus following perforant path LTP induction in vivo (Lynch et al., 1994). These studies suggest activity-dependent synthesis and perhaps transport of presynaptic proteins. In vitro studies of synaptogenesis have shown that components of the active zone are transported along the axons (Friedman et al., 2000; Roos and Kelly, 2000). This transport is thought to be necessary both for synaptogenesis and the maintenance of functional neurotransmitter release sites. Activity dependence of axonal transport has recently been shown for transport of active zone precursor proteins by a syntaxinsyntabulin-KIF5B complex along axonal microtubules (Cai et al., 2007). Additionally, the study by Cai et al. (2007) established the importance of axonal microtubules for transport of components of the presynaptic active zone.

Our data suggest that high-frequency activation of granule neurons induces plasticity-related processes both at MF terminals and at granule cell somata, and that both sets of processes are required for long-term changes in MF synaptic transmission. Induction of somatic protein synthesis and the transport of component proteins of the active zone to synaptic terminals may then promote plastic changes in presynaptic neurotransmitter release.

\section{References}

Brown JT, Randall AD (2009) Activity-dependent depression of the spike after-depolarization generates long-lasting intrinsic plasticity in hippocampal CA3 pyramidal neurons. J Physiol 587:1265-1281.

Cai Q, Pan PY, Sheng ZH (2007) Syntabulin-kinesin-1 family member 5Bmediated axonal transport contributes to activity-dependent presynaptic assembly. J Neurosci 27:7284-7296.

Calixto E, Thiels E, Klann E, Barrionuevo G (2003) Early maintenance of hippocampal mossy fiber-long-term potentiation depends on protein and RNA synthesis and presynaptic granule cell integrity. J Neurosci 23:4842-4849.

Castillo PE, Weisskopf MG, Nicoll RA (1994) The role of $\mathrm{Ca}^{2+}$ channels in hippocampal mossy fiber synaptic transmission and long-term potentiation. Neuron 12:261-269.

Castillo PE, Janz R, Südhof TC, Tzounopoulos T, Malenka RC, Nicoll RA (1997) Rab3A is essential for mossy fibre long-term potentiation in the hippocampus. Nature 388:590-593.

Castillo PE, Schoch S, Schmitz F, Südhof TC, Malenka RC (2002)
RIMlalpha is required for presynaptic long-term potentiation. Nature 415:327-330.

Dietrich D, Kirschstein T, Kukley M, Pereverzev A, von der Brelie C, Schneider T, Beck H (2003) Functional specialization of presynaptic $\mathrm{Ca}_{\mathrm{v}} 2.3 \mathrm{Ca}^{2+}$ channels. Neuron 39:483-496.

Dombeck DA, Kasischke KA, Vishwasrao HD, Ingelsson M, Hyman BT, Webb WW (2003) Uniform polarity microtubule assemblies imaged in native brain tissue by second-harmonic generation microscopy. Proc Natl Acad Sci U S A 100:7081-7086.

Friedman HV, Bresler T, Garner CC, Ziv NE (2000) Assembly of new individual excitatory synapses: time course and temporal order of synaptic molecule recruitment. Neuron 27:57-69.

Gitler D, Spira ME (1998) Real time imaging of calcium-induced localized proteolytic activity after axotomy and its relation to growth cone formation. Neuron 20:1123-1135.

Helme-Guizon A, Davis S, Israel M, Lesbats B, Mallet J, Laroche S, Hicks A (1998) Increase in syntaxin 1B and glutamate release in mossy fibre terminals following induction of LTP in the dentate gyrus: a candidate molecular mechanism underlying transsynaptic plasticity. Eur J Neurosci 10:2231-2237.

Hicks A, Davis S, Rodger J, Helme-Guizon A, Laroche S, Mallet J (1997) Synapsin I and syntaxin 1B: key elements in the control of neurotransmitter release are regulated by neuronal activation and long-term potentiation in vivo. Neuroscience 79:329-340.

Kwan AC, Dombeck DA, Webb WW (2008) Polarized microtubule arrays in apical dendrites and axons. Proc Natl Acad Sci U S A 105: $11370-11375$.

Lynch MA, Voss KL, Rodriguez J, Bliss TV (1994) Increase in synaptic vesicle proteins accompanies long-term potentiation in the dentate gyrus. Neuroscience 60:1-5.

Madison DV, Malenka RC, Nicoll RA (1991) Mechanisms underlying long-term potentiation of synaptic transmission. Annu Rev Neurosci 14:379-397.

Mandolesi G, Madeddu F, Bozzi Y, Maffei L, Ratto GM (2004) Acute physiological response of mammalian central neurons to axotomy: ionic regulation and electrical activity. FASEB J 18:1934-1936.

Mellor J, Nicoll RA (2001) Hippocampal mossy fiber LTP is independent of postsynaptic calcium. Nat Neurosci 4:125-126.

Nicoll RA (2003) Expression mechanisms underlying long-term potentiation: a postsynaptic view. Philos Trans R Soc Lond B Biol Sci 358:721-726.

Nicoll RA, Malenka RC (1995) Contrasting properties of two forms of longterm potentiation in the hippocampus. Nature 377:115-118.

Nicoll RA, Schmitz D (2005) Synaptic plasticity at hippocampal mossy fibre synapses. Nat Rev Neurosci 6:863-876.

Roos J, Kelly RB (2000) Preassembly and transport of nerve terminals: a new concept of axonal transport. Nat Neurosci 3:415-417.

Vickers CA, Wyllie DJ (2007) Late-phase, protein synthesis-dependent long-term potentiation in hippocampal CA1 pyramidal neurones with destabilized microtubule networks. Br J Pharmacol 151:1071-1077.

Yeckel MF, Kapur A, Johnston D (1999) Multiple forms of LTP in hippocampal CA3 neurons use a common postsynaptic mechanism. Nat Neurosci 2:625-633.

Ziv NE, Spira ME (1997) Localized and transient elevations of intracellular $\mathrm{Ca}^{2+}$ induce the dedifferentiation of axonal segments into growth cones. J Neurosci 17:3568-3579. 